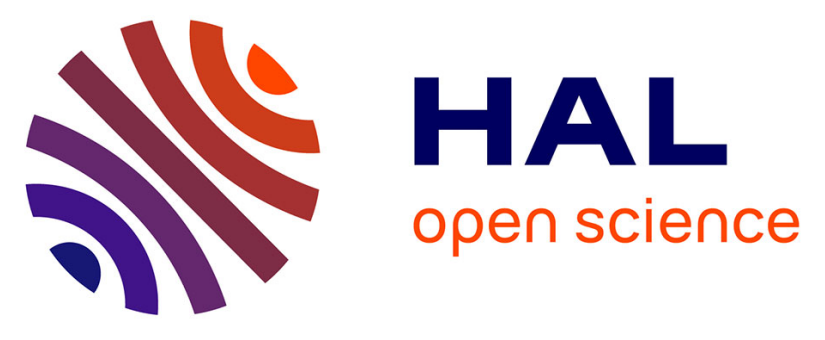

\title{
Influence of Eye Diseases on the Retina Pattern Recognition
}

\author{
Emil Saeed, Anna Bartocha, Piotr Wachulec, Khalid Saeed
}

\section{To cite this version:}

Emil Saeed, Anna Bartocha, Piotr Wachulec, Khalid Saeed. Influence of Eye Diseases on the Retina Pattern Recognition. 13th IFIP International Conference on Computer Information Systems and Industrial Management (CISIM), Nov 2014, Ho Chi Minh City, Vietnam. pp.130-140, 10.1007/9783-662-45237-0_14. hal-01405571

\section{HAL Id: hal-01405571 \\ https://hal.inria.fr/hal-01405571}

Submitted on 30 Nov 2016

HAL is a multi-disciplinary open access archive for the deposit and dissemination of scientific research documents, whether they are published or not. The documents may come from teaching and research institutions in France or abroad, or from public or private research centers.
L'archive ouverte pluridisciplinaire HAL, est destinée au dépôt et à la diffusion de documents scientifiques de niveau recherche, publiés ou non, émanant des établissements d'enseignement et de recherche français ou étrangers, des laboratoires publics ou privés.

\section{(c)(1)}

Distributed under a Creative Commons Attribution| 4.0 International License 


\title{
Influence of eye diseases on the retina pattern recognition
}

\author{
${ }^{1}$ Emil Saeed, ${ }^{2}$ Anna Bartocha, ${ }^{3}$ Piotr Wachulec, ${ }^{4,5}$ Khalid Saeed \\ ${ }^{1}$ Department of Ophthalmology, Faculty of Medicine, Medical University of Bialystok, Poland \\ ${ }^{2,3,4}$ Faculty of Physics and Applied Computer Science, AGH UST in Krakow, Poland \\ ${ }^{5}$ Faculty of Computer Science, Bialystok University of Technology, Poland \\ 1emilsaeed1986@gmail.com, ${ }^{2}$ bartochaanna@gmail.com, ${ }^{3}$ pioxan@gmail.com, \\ saeed@agh.edu.pl
}

\begin{abstract}
In this paper an algorithm to extract the retina characteristic points for a human eye with diseases is presented. The background of both medical and computer science matters is given. The cataract is described and discussed as a newly considered eye disease for retina pattern recognition. The processing of the retina with this disease is introduced for comparison with previous works. The structure of the applied method is illustrated in detail with examples. The procedure of minutiae extraction from the processed sick retina is given.
\end{abstract}

Keywords. Biometrics, Human identification, Identification of retina with anomalies, Retina diseases.

\section{Introduction}

The retina consists of many layers causing it to be of highly complicated structure. Optic disc is a location on the retina where the optic nerve exits the eye. It is also the entry point for the major blood vessels that supply the retina.

We use retina blood vessels to recognize people because human retina is unique [1]. Even identical twins do not share a similar pattern of the blood vessels network in the retina. However, serious retina diseases, may cause problems in its pattern identification. A detailed discussion of such diseases is given by authors in [2]. In this paper, however, a brief study is presented to show the influence of some retina diseases on its recognition. In this section we are listing them for the reader convenience.

\section{Central retinal artery occlusion, where a part of the artery may be unseen.}

It is a disease where blood flow through retinal artery is blocked. The patient complains of sudden painless loss of vision. Cholesterol and calcific emboli may result in permanent obstruction. Sometimes the artery can recapitalize with time. Acute treatment of central and branch artery occlusions is aimed at dilating the arteriole to permit the embolus to pass more distally and limit the damage. Results are 
usually disappointing. Prolonged arterial occlusion results in severe, unrecoverable visual loss.

\section{Central retinal vein occlusion}

This may result from abnormality of blood itself, an inflammation or an increased ocular pressure. The patient complains of sudden partial or complete loss of vision. Retinal laser treatment is given when it is necessary, some drugs can be taken such as rutoside, especially when we observe hemorrhages.

\section{Retinal detachment - which may hide the retinal vessels}

Patient notices the progressive development of a field defect, described as a 'shadow' or 'curtain'. It can be treated - surgically.

Sometimes, it is impossible to assess the retina because of the cataract (Fig. 2). Opacification of the lens of the eye (cataract) is the most common cause of treatable blindness in the world. The large majority of the cataracts occur in older subjects, as a result of cumulative exposure to environmental and other influences such as smoking, UV radiation and elevated blood sugar levels. A smaller number of cataracts is associated with specific ocular or systemic disease (for example hypocalcemia, infection, systemic drugs particularly steroids) and defined physicochemical mechanisms. Some are congenital and may be inherited. An opacity in the lens of the eye causes a painless loss of vision, glare and may change refractive error. Visual acuity is reduced.

A cataract appears black against the red reflex when the eye is examined with the direct ophthalmoscope. Slit lamp examination allows the cataract to be examined in detail, and the exact site of the opacity in the lens can be identified. It also can be treated - only surgically.

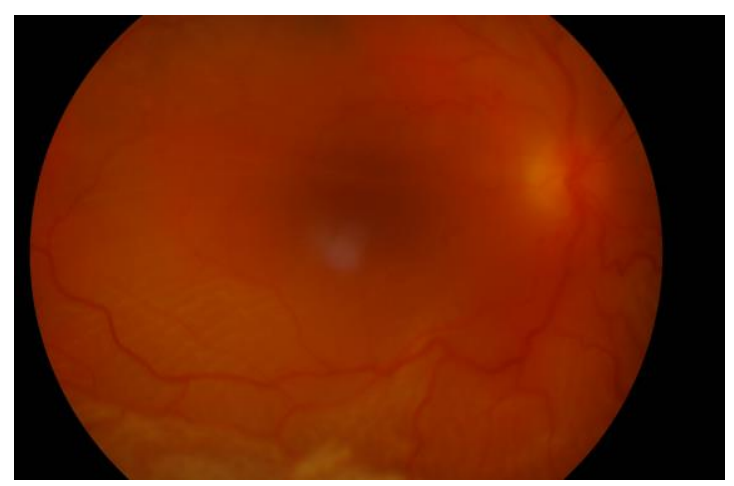

Fig. 1. Peripheral retinal detachment in eye with cataract 


\section{Retina Pattern Algorithm}

I previous work [2] the authors presented their methodology giving the theory in a computer flowchart whilst the computer implementation was left to a future work. Here, in this paper, the pseudocode of the algorithm is given with some result examples.

\section{Computer program pseudocode}

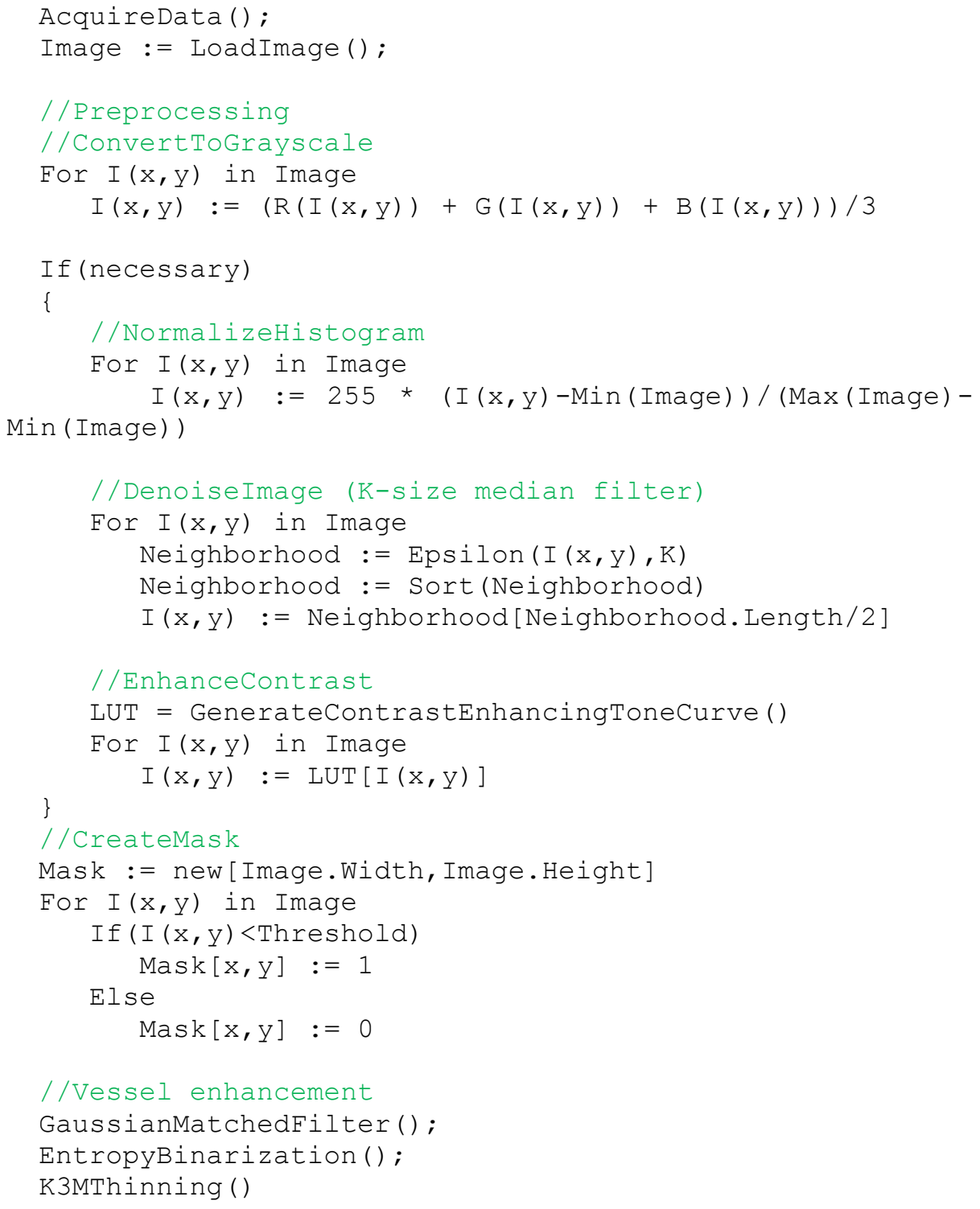




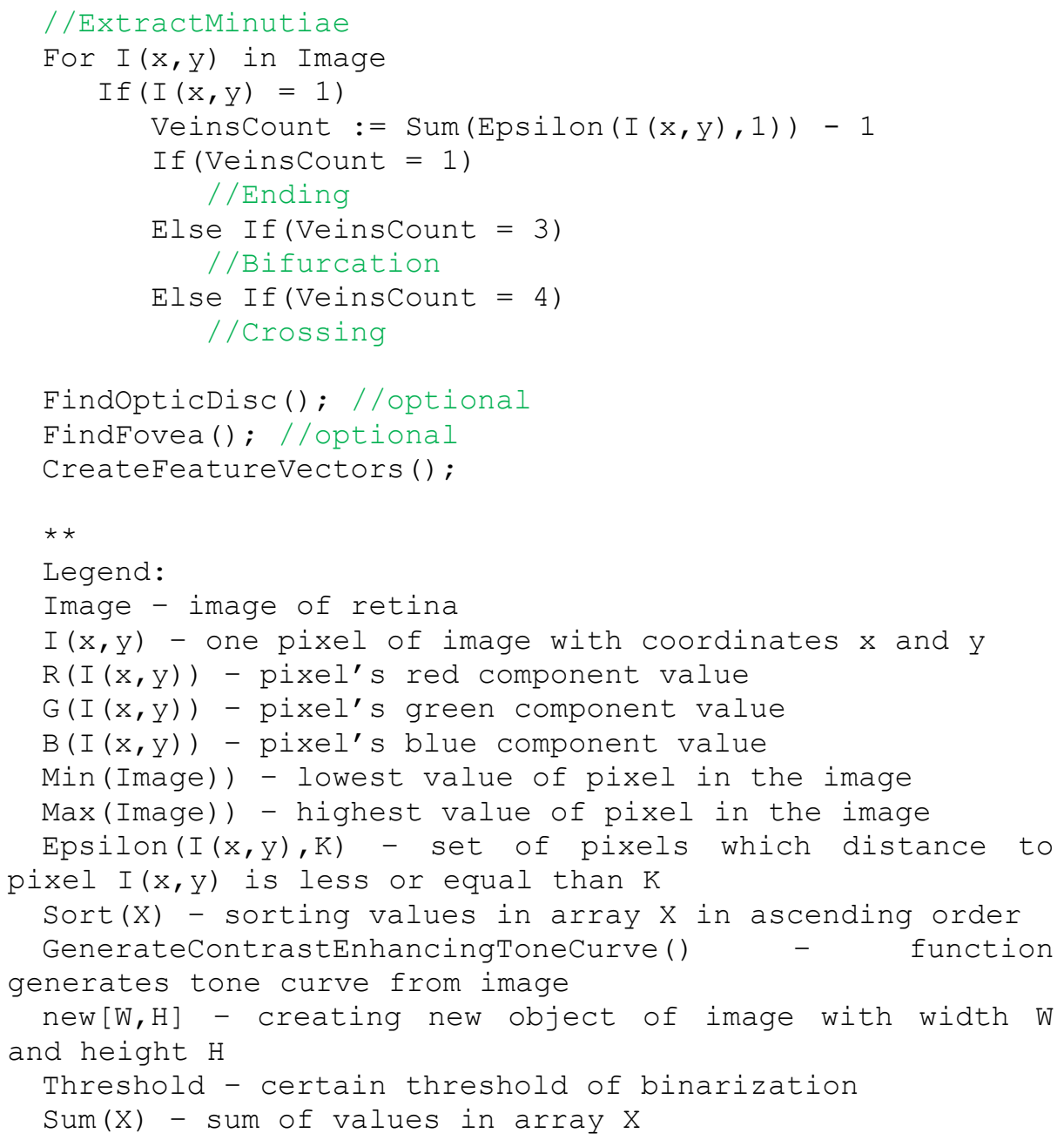

The algorithm steps involve preprocessing, mask creation, vessel segmentation patter thinning, minutiae extraction and feature vector creation.

The image is first denoised contrast enhancement, conversion to greyscale and histogram normalization.

It is noticed that retinal vessel are the best visible on green color channel. Because of this fact, we can use only that layer for searching of minutiae.

The next step is vessel enhancement and segmentation with binarization. One of the approaches is using Gaussian Matched Filter [3] and then binarization (for example Local Entropy Thresholding [4][5]). Blood vessels usually have poor local contrast and edge detection algorithms results are not sufficient. In Gaussian Matched Filter method we receive grayscale image approximated by Gaussian shaped curve. 
The aim is to detect piecewise linear segments of blood vessels so we create 12 different mask filters and search for vessels in every 15 degrees. Fig. 2 shows the retina vessels after segmentation and enhancement.

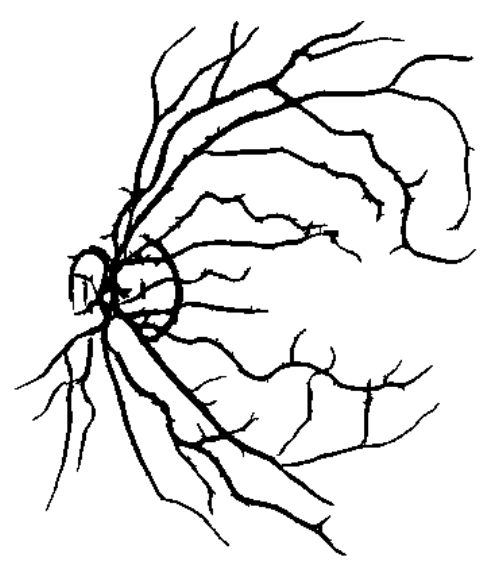

Fig. 2. Retina image after vessel segmentation and enhancement.

Then the retina image is thinned. This operation allows to get the image skeleton. In our work K3M [6] is used and the thinning result is shown in Fig.3.

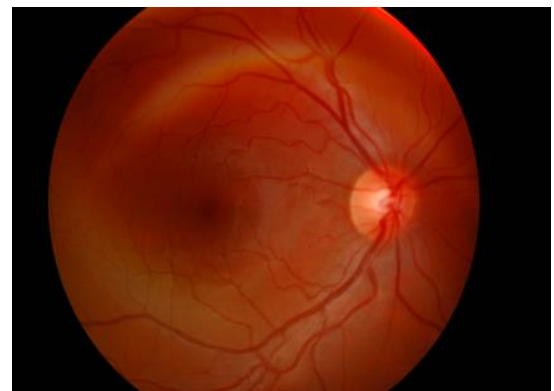

(a)

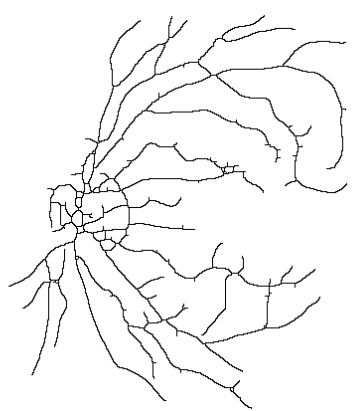

(b)

Fig. 3. Retina image (a) and its skeleton (b)

The next step to find bifurcations, crossings and end points of vessels. It can be done with the aid of masks. Examples of retina minutiae are shown in Fig. 4. 


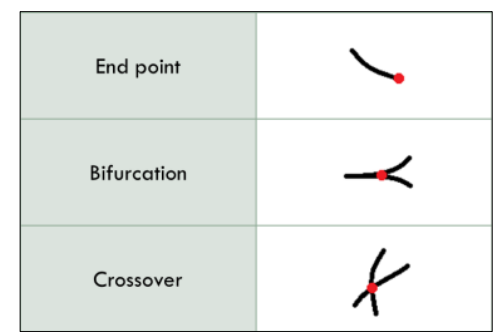

Fig. 4. Selected types of retina minutiae

This will help find the essential characteristic points for the whole retina pattern (Fig. $5)$. This way the feature vector is built on the basis of the feature points location $[1,7]$.

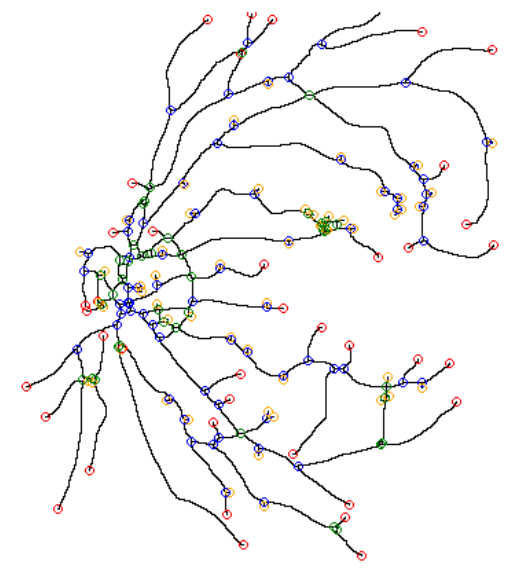

Fig. 5. Retina image after finding minutiae

The optic discs can also be located by identifying the area with the highest variation in intensity of adjacent pixels [7].

This feature vector will be used in classification process.

For classification, the algorithm follows Euclidean Distance or Manhattan Distance $[2]$.

\section{Experimental Results}

The healthy retina gives the processing results shown in Fig 6. 

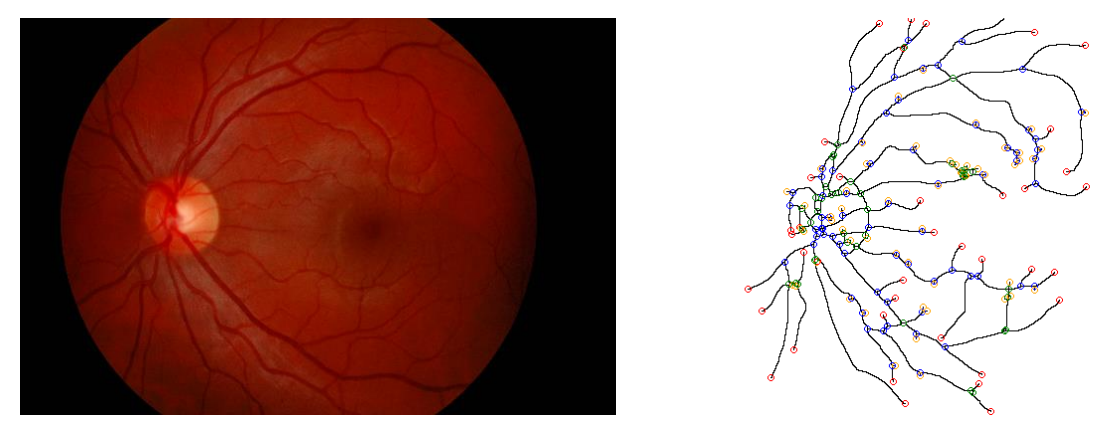

Fig. 6. Healthy retina - input images and results

Retina with one of the mentioned above diseases (section 1) or defects will furnish different images of its pattern. Therefore, the preprocessing steps will give results a little diverged from the healthy eye. Figures 7-10 show the results of treating such cases.
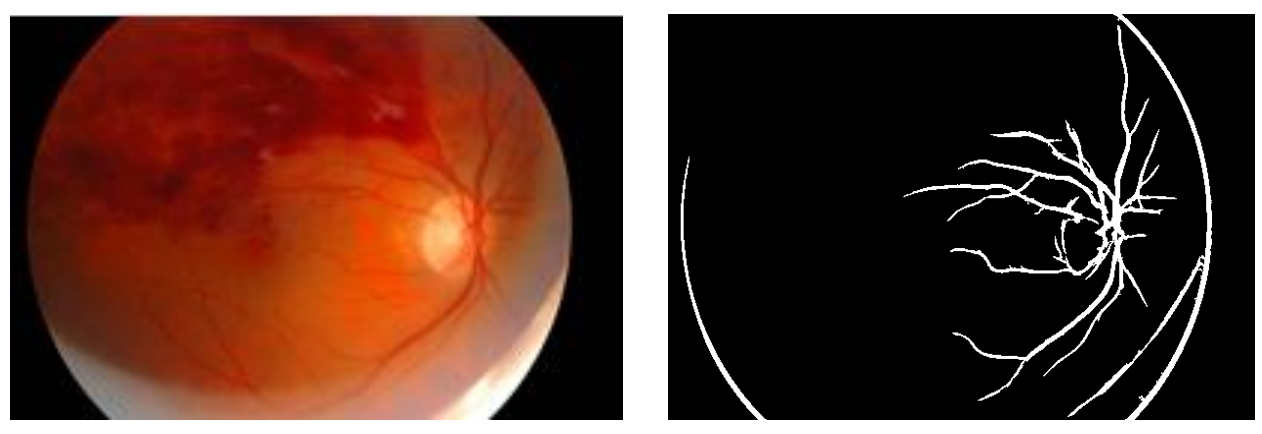

(a) Vessel enhancement
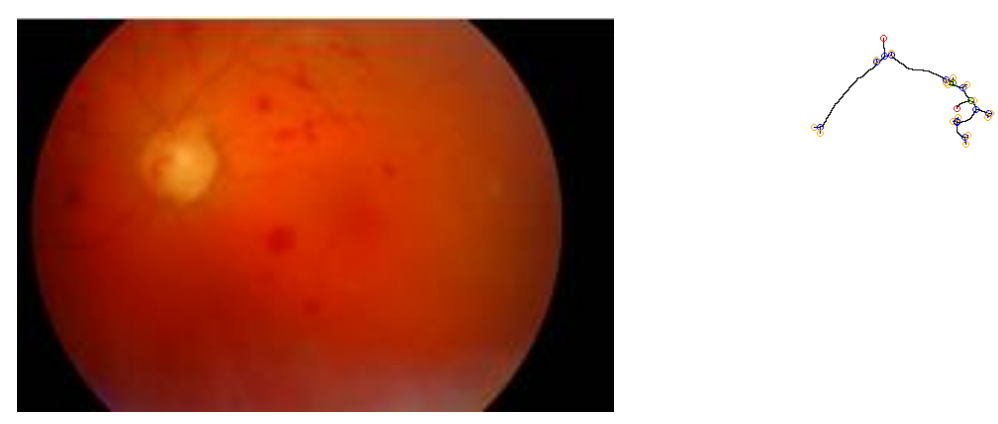

(b) Minutiae extraction 

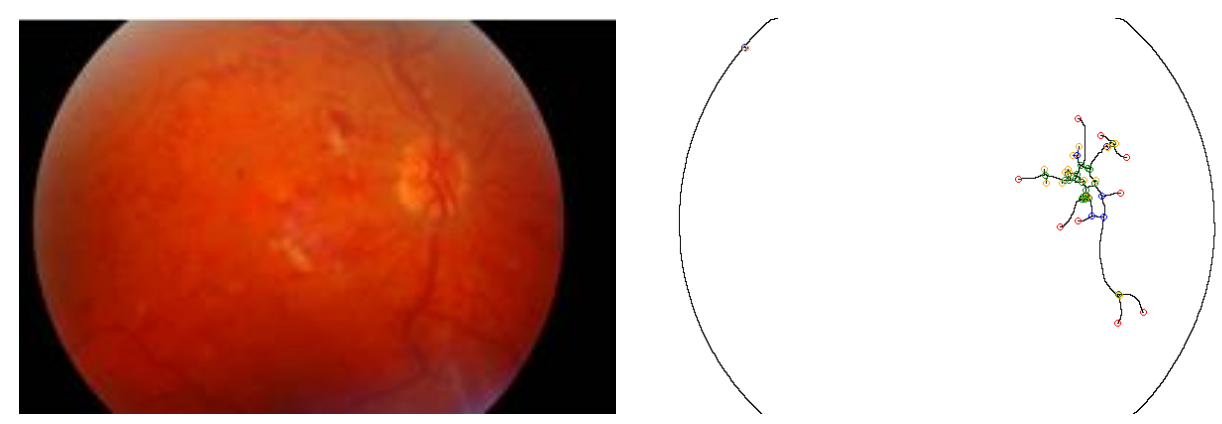

(c) Minutiae extraction
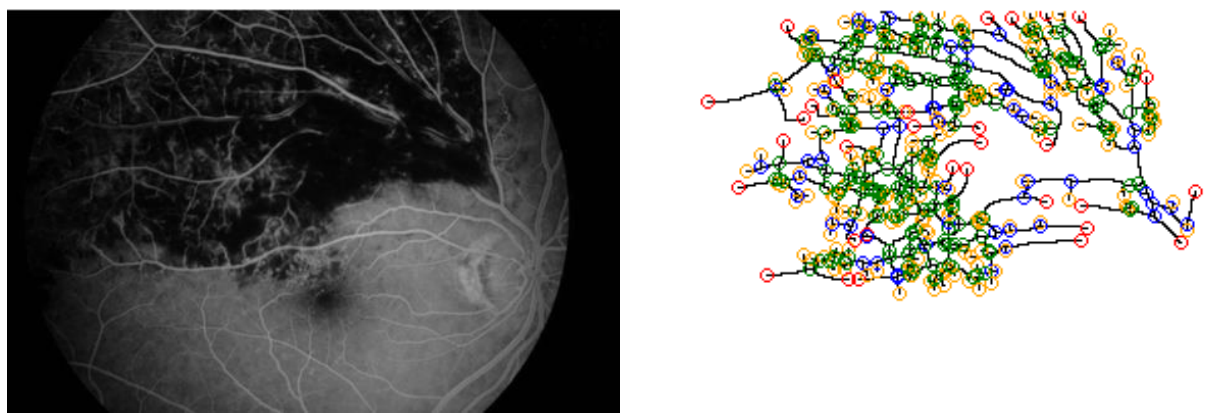

(d) Minutiae extraction
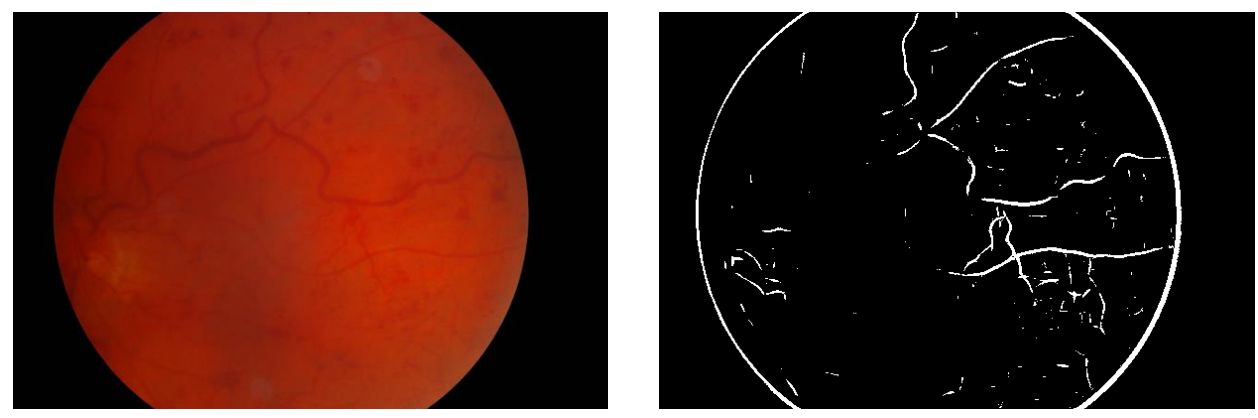

(e) Vessel enhancement 

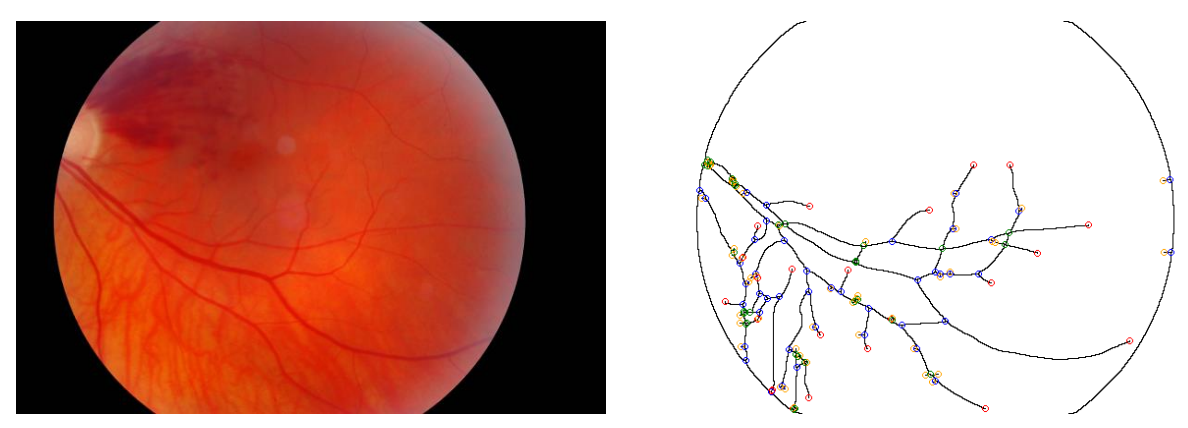

(f) Minutiae extraction

Fig. 7. Vein occlusion - input images and processing results. Vein occlusion makes veins ragged so algorithm removes huge part of them. It results in large losses of data (images b, c, d) which is required to confident recognition. In image (e) due to stain of blood we find a lot of false minutiae which makes recognition even harder.

It is worthy noticing that the artery occlusion creates same problems as vein occlusion [2]. A lot of ragged veins results in significant loss of data. From the other side, significant retinal detachment makes recognition impossible because we lose almost the whole data [2] except some certain cases.

Retinal hemorrhage (Fig. 8) results in large loss of data, so recognition success and possibility is heavily dependent on its scale and location. We have to remember that treatment is possible and the whole blood may disappear.

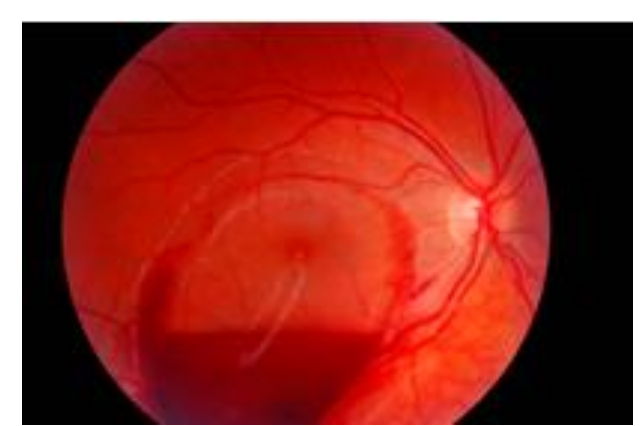

(a)

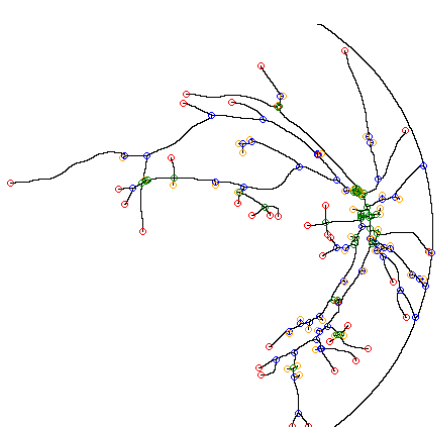

(b)

Fig. 8. Retinal hemorrhage - input image (a) and feature extract results (b)

Optic nerve (Fig. 9) head inflammation do not change pattern of the veins so recognition should be still possible. 

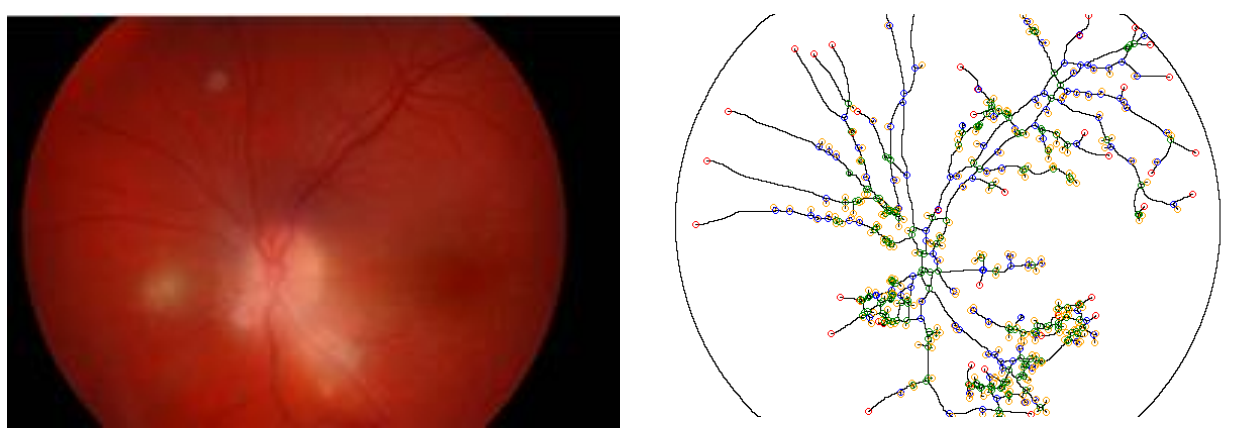

Fig. 9. Optic nerve head inflammation - input images and results

Another eye disease is cataract (lens clouding), which shows completely different processing results (Fig. 10). It removes almost the whole data, making recognition impossible. Cataract surgery is very common nowadays, and it results in transparent vision, which makes recognition possible.
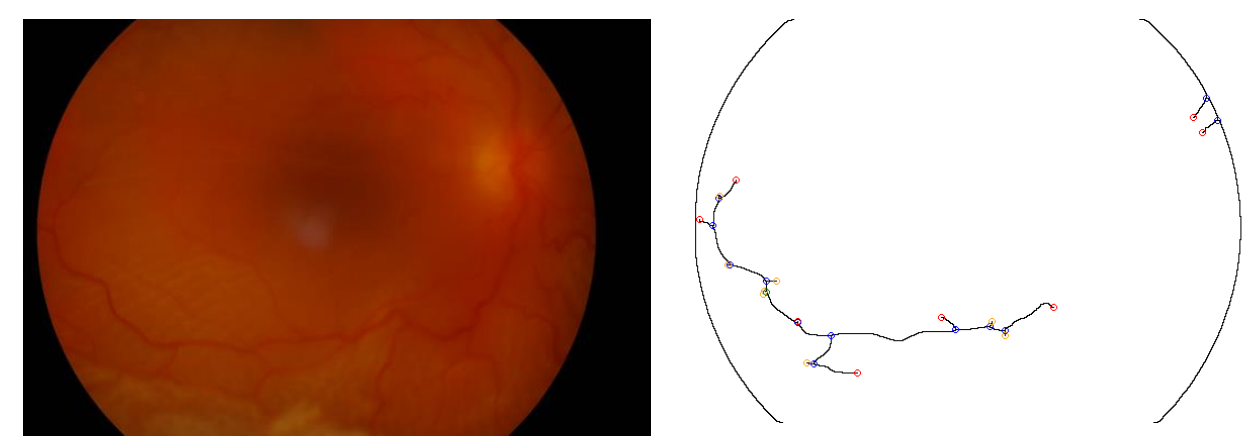

Fig. 10. Cataract - input images and results

\section{Result Analysis and Conclusions}

As we can see, there is a difference in features (quantitative and locally) between the healthy and diseased eye. Vein occlusion and artery occlusion often result in dashed veins after the usage of Gaussian Matched Filter. Current version of the algorithm cannot recover that state, and hence a large part of information is lost during the cleaning step (denoising and enhancement, ... ) which proceeds the thinning stage. Most of the eye diseases and particularly those which hit the retina would hide some parts of the retina would definitely cause data loss and makes recognition much harder and less confident. 
On the other hand some diseases have only minimal influence like optic nerve head inflammation or retina detachment after successful treatment.

Authors are working on more cases and classification of new disease examples to prove the efficiency of the algorithm in treating general cases.

In the current state, the conclusion is that sick retina cannot guarantee good algorithm results and the successful recognition is therefore affected. However, this requires further research before giving the final definite decision on the sick retina identification results. This way we may at least exclude some of the diseases that would affect the results in a hundred percent.

\section{Acknowledgement}

The research was partially supported by grant no. WFiIS 11.11.220.01/Saeed, AGH University of Science and Technology in Krakow.

\section{References}

[1] M. Villalobos-Castaldi, E. M. Felipe-Riverón, "Fast Automatic Retinal Vessel Segmentation and Vascular Landmarks Extraction Method for Biometric Applications", IEEE International Conference on Biometrics, Identity and Security, 2009

[2] A. Bartocha, E. Saeed, P. Wachulec, K. Saeed, "Algorithm for Retina Recognition," International Conference on Applied Computation and Security Systems (ACSS), proceeding on CD, 2014.

[3] S. Chaudhuri, S. Chatterjee, N. Katz, M. Nelson, M. Goldbaum, "Detection of Blood Vessels in Retinal Images Using Two-Dimensional Matched Filters", IEEE Transactions of Medical Imaging, vol. 8, no. 3, 1989

[4] T. Chanwimaluang, G. Fan, "An Efficient Blood Vessel Detection Algorithm for Retinal Images Using Local Entropy Thresholding," Proceedings of the 2003 International Symposium on Circuits and Systems, vol.5, pp.21-24, May 2003

[5] Z. HongQing, "Segmentation of Blood Vessels in Retinal Images using 2-D Entropies of Gray Level-Gradient Co-occurrence Matrix", ICASSP 2004

[6] K. Saeed, M. Rybnik, M. Tabedzki, M. Adamski, " K3M: A Universal algorithm for Image Skeletonization and Review of Thinning Techniques", Int. J. Appl. Math. Comput. Sci., 2010, vol. 20, No. 2, 317-335

[7] C. Sinthanayothin, J. F. Boyce, H. L. Cook, T. H. Williamson, "Automated localisation of the optic disc, fovea, and retinal blood vessels from digital colour fundus images", 1999 